Logos Universality Mentality Education Novelty, Section: Social Sciences

ISSN: $2284-5747$ (print), ISSN: $2284-5747$ (electronic)

Covered in: CEEOL, Index Copernicus, Ideas RePEc, EconPapers, Socionet

\title{
IDEOLOGY OF ORIGIN EFFECT - A CONVERSION OF THE COUNTRY OF ORIGIN EFFECT
}

\section{Mădălina MANOLACHE}

Logos Universality Mentality Education Novelty, Section:

Social Sciences, 2015, IV (1), 15-21

The online version of this article can be found at: http://lumenjournals.com/social-sciences/

\footnotetext{
Published by:

Lumen Publishing House

On behalf of:

Lumen Research Center in Social and Humanistic Sciences
} 


\title{
Ideology of Origin Effect - a Conversion of the Country of Origin Effect
}

\author{
Mădălina MANOLACHE
}

\begin{abstract}
This paper is a follow-up of the first paper presented at Lumen 2014 conference on conversions entailed by the Europeanization concept in relation to the local adaptation versus standardization dilemma. It is our intention in this paper to focus on the ideology of origin effect, which resulted from the conceptual conversion of the country of origin effect from classical marketing. The conversion was part of our research dissertation on cognitive mapping of consonant and/or dissonant communicative contexts. We consider that this effect can be applied to the individual communicator, as the sender in an ideological communication process, by a complex recipient, such as the citizen(s) or the final beneficiaries of a policy, be they communities or individuals. The effect deals with ideas, beliefs, knowledge, judgements, emotions, social representations and conceptual networks, all deriving from what defines an ideology (Van Dijk, 2005). Being sharable, ideologies expose the social opinions of a group, which in turn cluster in a more familiar marketing notion, namely an attitude. Ideology can also be considered as a self-sufficient schemata of interpretation for the Us vs. Them representation as social groups.
\end{abstract}

\section{Keywords:}

clusters of representation, ideology of origin, country of origin, ideology, judgements, social representation(s)

1 PhD, "Vasile Alecsandri” University of Bacău, Romania,
manolachemadalina1982@gmail.com.

Manolache, M. (2015). Ideology of Origin Effect - a Conversion of the Country of Origin Effect. Logos Universality Mentality Education Novelty, Section: Social Sciences, IV (1), 15-21. 


\section{Introduction}

The conversion of the country-of-origin (Vrontis \& Thrassou, 2007) effect from classical marketing into the ideology-of-origin effect, from a marketing of ideas (Fine, 1981) approach, was necessary in order to make the cognitive mapping of the EU's communication processes on gender policy possible. Studies on Europeanization and especially on the European public sphere are deeply connected with concepts like integration process and governance and the communicative flows between the Union and it's citizens are perceived as being dependent, even too much in some cases, on the national media.

In order to go beyond this dependency, we concentrated our analysis on the formation of communities within the European public space, a process which we perceived as inter-connected with the conceptual activation of the ideologies within these communities. We opted for the process of conceptual activation to be done by using conceptual nodes which play the part of re/deactivators on a certain topic inside a specific community.

Our opinions on this conversion present proof within the data we collected from the policy documents on gender, that were issued by the European Commission for two periods, and from the online platforms of specialized communicative actors, such as stakeholders, media and a European communication network. The analysis of the data was done using framing analysis and data and text mining through a CAQDAS software. The results helped us to uncover four concepts which activtated consonant and disonant communicative contexts. In this paper we shall present the definition we used as a starting point for our conversion, the elements of the country of origin effect and our interpretation of some of these elements within the frame of ideological conversion, where the hybrid marketing product was the gender policy.

\subsection{What is ideology?}

Ideologies do not refer to the vision over the world of a certain group, but to the principles that lie beneath this vision. They are defined at a macro level, in terms of social groups, group relations, institutions and at micro level, in terms of social praxis. Van Dijk insists upon the fact that ideologies are built, used and changed by social actors, as members 
of a specific group within specific, often discoursive social practices (Van Dijk, 1998:8). As such, ideologies become social constructs shared by a group.

Ideologies have always been associated to convictions shared by society, where convictions were perceived as the constructive elements of the mind. As such, knowledge has been defined in this case as those convictions considered to be real upon truth criteria, which vary according to social, cultural and historic aspects. Van Dijk chose as working definition for convictions as representations derived from and involved in the actions of information processing which dwell inside the memory. Therefore we believe that convictions can be built, stored, reactivated and organised in macro-units, where all these processes help cognitive tasks to be handled.

As such a conviction can be represented as a network of conceptual nodes connected through specific routes. A network can be perceived as an interpretation macro-schemata, in which relations between concepts are better delineated. Each connection between the nodes can have a specific weight (namely relevance) and strength (positive or negative) according to the tempo of usage/(re/de)activation. Therefore, ideologies can be perceived as clusters of convictions from within the memory of individuals, but this memory is the social memory, defined from a psychological approach as the shared convictions of the individual with society.

\subsection{What is the country of origin effect - definition and structure}

Among the factors with a considerable impact on international competitivity, the research community believes that the country of origin effect holds considerable value and deserves special attention (AlSulaiti \& Baker, 1998). The most frequent definition of the effect is the one provided by Johansson: "the picture, the reputation, the stereotype that businessmen and consumers attach to products from a certain country" (Johansson, 2005).

According to Vrontis \& Thrassou, the structure of the effect refers to the following elements:

$$
\begin{array}{ll}
\text { - } & \text { "experience; } \\
\text { - } & \text { knowledge; } \\
\text { - } & \text { stereotypes; }
\end{array}
$$


- ethnocentrism;

- political and/or cultural relationship between country-of-origin and country-of-purchase;

- general country-of-origin image;

- specific-to-product-in-question country-of-origin image;

- brand image;

- country-of-purchase political, social and economic factors;

- target segment specifics".

The first component deals with consumer experience with the product, derived either from extensive use of the product or from a change in the quality of that product over time (Ahmed and d'Astous, 1993). As an additional impact, a positive or a negative experience with products from a specific country may influence the evaluations of other products or brands from the same country (Johansson et al., 1985 apud Vrontis, Thrassou \& Vignali, 2006)

Studies about the second element, namely product knowledge have showed that the "quantity of knowledge that customers have is not only useful for information search and has an effect on it, but also has an influence on the decision making procedures, and, moreover, on customer purchase intention.” (Hanzaee \& Khosrozadeh, 2011).

Stereotypes are used "to simplify and reduce information to a manageable level while often associating a particular attitude with that information" (Hinner, 2010). In order to manage information overload, categorization and afterwards associations offer the consumers the possibility to deal with novelty and product choices by a simple mechanism of conceptual labelling and association. The intricacy of the stereotyping mechanisms has to do with perceptual processes and impression management (Grunig, 1993).

Ethnocentrism is "another definition related to patriotism about the customers who have a tendency to buy domestic products and brands." (Rezvani et.al, 2012). It is defined in terms of "ingroup/outgroup orientation" (Lantz \& Loeb, 1996) where the ingroup holds preference and the members position themselves in opposition to the outgroup. 


\subsection{Converted model}

In this paper we shall only focus on the first four elements of the previously presented model.

In our proposed model we associated the experience component to what is known as episodic memory. Van Dijk defines it as "part of memory where beliefs are stored about concrete episodes (facts, events, situations, etc.)" we took part in or about which others have provided information. Thus episodic memory incorporates the personal experiences, retained under the form of representations and cognitive processes. Thus, the message embedded in a campaign on a specific policy might not trigger the expected results anticipated by an institutional communicator at the level of specialized and complex receivers if their retained representations of that policy have no positive associations or episodes.

The knowledge component was associated with beliefs, as they are the constructive elements of the mind. Knowledge is thus defined as those beliefs considered to be true on the basis of truth criteria, variable according to social, cultural and historic aspects. The beliefs are considered by Van Dijk as representations which result from and are involved in processing acts of information which take place inside the memory. Thus, shifts in policy, especially when the individual communicator changes, pave the way for processing routes which, in our opinion, can be dealt with only if the evaluation criteria inside the collective memory are not altered. More specificaly, If the values embedded in these beliefs do not alter their meaning when they find projected associations inside the policy messages, than the processing is consonant. But when these projected associations have negative effects in terms of social and cultural praxis, than the process is dissonantly activated.

The stereotypes element was identified with the social arrangements' component, where by social arrangement we understand generated values with a specific ideological content. Values are considered to be evaluative criteria, but when the meaning of one value is adjusted and it holds a relative meaning instead of a universal one, than the conceptual power of that value is permeated with ideological content. Also, when the communities agree to this transformed conceptual power, than the social arrangement dictates new perceptual paths, namely new labelling 
processes. The dealing with information overload is handled in a persuasive manner from the start.

Ethnocentrism has been associated with what Van Dijk defines as truth criteria, which are "generally cultural, but differently applied", meaning that for each community an individual communicator on a policy may use a unique truth criteria but apply it differently. The only problem with policies is that truth and truth criteria are usually negotiated before they are communicated.

\subsection{Conclusions}

Our portrayal of these conversions should be considered $a$ conceptual work in progress. Each of the conversion segments mentioned in this paper require in-depth research, since they imply a mix of research domains and methodologies, especially in the current context of glocal instruments of communication, which alter the communicative processes and the level of unveiling in policy matters. The logic of conversion needs to balance the coherence embedded in the conceptual tools in order for the similarities in the conceptual mechanisms to emerge. In our case, the main paradigm of the marketing of ideas ensured this logic, as it is considered that ideas can be managed like any other product, as they are for problems what goods and services are for basic needs.

\section{References}

Ahmed, S. A. and d'Astous, A. (1993) Crossnational evaluation of madein concept using multiple cues. European Journal of Marketing, MCB University Press, 27(7), pp.39-52.

Al-Sulaiti, K.-I., Baker, M.-J. (1998) Country of origin effects: a literature review. Marketing Intelligence \& Planning, 16(3), 150-199

Fine, S. H. (1981). The marketing of ideas and social issues. Praeger Publishers.

Grunig, J. (1993). Image and Substance: From Symbolic to Behavioral Relationships, Public Relations Review, 19(2), 121-139.

Hanzaee, K. H., \& Khosrozadeh, S. (2011). The Effect of the Countryof-Origin Image, Product Knowledge and Product Involvement on Information Search and Purchase Intention. Middle-East Journal of Scientific Research, 8(3), 625-636. 
Hinner, M. (2010). Stereotyping and the Country-of-Origin Effect. China Media Research, 6(1), 47-51.

Lantz, G., Loeb, S. (2012). Country of Origin and Ethnocentrism: An Analysis of Canadian and American Preferences using Social Identity Theory. Advances in Consumer Research, 23, 374-378.

Rezvani, S., Dehkordi, J.G., Rahman, M. S., Fouladivanda, F., Habibi, M., Eghtebasi, S. (2012). A Conceptual Study on the Country of Origin Effect on Consumer Purchase Intention. Asian Social Science, 8(12), 205-215

Vrontis, D., \& Thrassou, A. (2007). Adaptation vs. Standardization in international marketing-the country-of-origin effect. Innovative Marketing, 3(4), 7-20.

Vrontis, D., Thrassou, A. \& Vignali, C. (2006). The country-of-origin effect on the purchase intention of apparel. Int. J. Entrepreneurship and Small Business, 3(3/4).

\section{Biodata}

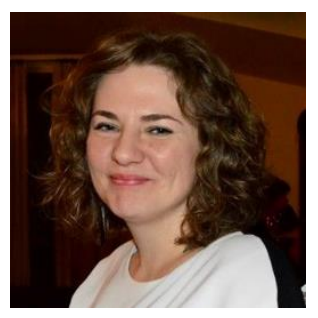

Madalina MANOLACHE works as a Communication Consultant at Europe Direct Bacau Information Centre and is a member of ROASS and ECREA associations. She is 33 years old and holds a Doctorate in Marketing, from Transilvania University of Brasov, Romania. Her research interests cover topics such as: gender studies, social media, IMC, soft power, the EU and consumer behaviour. She has published articles on European Union communicative actors and on the communication instruments used within the public space of EU for topics like; equality, justice, rights, gender pay gap.

Manolache, M. (2015). Ideology of Origin Effect - a Conversion of the Country of Origin Effect. Logos Universality Mentality Education Novelty, Section: Social Sciences, IV (1), 15-21. 